\title{
DESAIN KAPAL PEMBANGKIT LISTRIK TENAGA ANGIN 15 GT UNTUK DAERAH PERAIRAN TERPENCIL WILAYAH TIMUR INDONESIA
}

\author{
Ali Imron ${ }^{1)}$, Budianto ${ }^{1)}$ \\ 1) Teknik Desain dan Konstruksi Kapal, Politeknik Perkapalan Negeri Surabaya, Indonesia \\ Email: ali.imron.as@gmail.com
}

\begin{abstract}
Abstrak
Dalam desain kapal pembangkit listrik tenaga angin (KPLTA) 15 GT yang memanfaatkan energi terbarukan yang ada, yakni energi angin untuk kepentingan hajat hidup rakyat, terutama masyarakat yang hidup di daerah perairan terpencil. Dimana masyarakat yang hidup di daerah yang belum teraliri oleh listrik, namun cukup berdekatan dengan daerah perairan seperti sungai, danau atapun pantai yang mempunyai hembusan angin yang kuat untuk mengerakan baling-baling kincir angin. KPLTA 15 GT tersebut, membantu masyarakat dalam memaksimalkan energi angin yang tersedia berlimpah. Kapal ikan kapasitas 15 GT yang semula hanya difungsikan sebagai kapal angkut penumpang ataupun kapal untuk menangkap ikan bias. Inovasi kini kapa, dilengkapi dengan peralatan kincir angin yang dapat mengubah energi angin menjadi energi listrik. Pembangkit listrik tenaga angin atau wind power system memanfaatkan angin melalui kincir, untuk menghasilkan energi listrik. Secara umum, sistem alat ini memanfaatkan hembusan angin untuk memutar baling-baling kincir angin, yang selanjutnya ditransmisikan untuk mengerakan generator DC yang didalamnya ada medan magnet yang dipotong oleh kumparan dari gerak poros rotor sehingga menghasilkan gaya gerak listrik (GGL) induksi atau arus listrik. Kemudian arus listrik DC tersebut disimpan kedalam baterai ataupun accu 12 Volt yang dapat dimanfaatkan langsung oleh masyarakat. Dalam desain kapal pembangkit listrik tenaga angin 15 GT didapatkan kapal dengan panjang Loa 15 m, lebar 7 meter dan memiliki kecepatan kapal mencapai 7 knots, dengan dilengkapi sistem pembangkit tenaga angin. Metode Perancangan dengan menggunakan simulasi model kapal bertujuan untuk menyesuaikan desain kapal dengan pembangkit listrik tenaga angin dengan memperhatikan resistance kapal dan kondisi operasional di wilyah timur perairan Indonesia.
\end{abstract}

Keyword: desain kapal, angin, kincir, listrik.

\section{PENDAHULUAN}

Sumber daya alam itu dibedakan menjadi dua kelompok, yaitu sumber daya alam yang dapat diperbarui atau hampir tidak dapat habis misalnya: tumbuhan, hewan, air, sinar matahari, angin, dan sebagainya. Sedangkan sumber daya alam yang tidak dapat diperbarui atau habis, misalnya: minyak bumi, bahan bakar fosil atau batu bara. Selanjutnya, secara terperinci energi dibedakan atas energi dapat diubah dari suatu bentuk ke bentuk energi lain. Misalnya, energi potensial air dapat diubah menjadi energi gerak, energi listrik, dan seterusnya. Energi listrik sangatlah penting bagi kehidupan kita. Bayangkan bagaimana jadinya kehidupan di bumi ini tanpa adanya listrik. Segala peralatan elektronik yang kita beli tidak akan berfungsi, tidak ada lampu penerangan dan proses produksi pun tidak akan berjalan sempurna.
Namun di sisi lain, kita masih menjumpai beberapa khususnya di daerah wilayah terpencil Indonesia yang belum teraliri listrik. Sungguh bukan perihal fakta yang menyenangkan untuk dibayangkan, saudara-saudara kita disana belum bisa menikmati keuntungan energi listrik seperti yang kita rasakan saat ini.

Dalam desain ini Kapal pembangkit listrik tenaga angin (KPLTA) 15 GT memaksimalkan energi terbarukan yang ada untuk kepentingan hajat hidup rakyat, terutama masyarakat yang hidup di daerah terpencil. Khususnya masyarakat yang hidup di daerah yang belum terjangkau oleh aliran listrik, namun cukup berdekatan dengan daerah perairan seperti sungai, danau ataupun pantai. Kapal PLTA 15 GT dapat membantu masyarakat dalam memaksimalkan energi yang tersedia, yakni energi angin. Energi angin yang dapat diubah menjadi energi listrik sangat 
membantu kelangsungan hidup mereka. Material yang digunakan menggunakan material FRP dimana dalam pelaksanaannya pembuatan lambung kapal lebih mudah untuk dibentuk, sehingga mendapatkan bentuk lambung kapal yang stream line yang dapat memaksimalkan aliran fluida menuju ke propeller kapal, sehingga memaksimalkan daya dorong kapal.

Dengan Proses simulasi modeling kapal dapat menentukan bagaimana konfigurasi dari sistem, kombinasi dari besarnya kapasitas komponenkomponen sistem, dan strategi operasi yang menentukan bagaimana komponen-komponen tersebut dapat bekerja bersama dalam operasional di kapal.

\section{TINJAUAN PUSTAKA}

\subsection{Pembangkit Listrik Tenaga Angin}

Secara umum, pemakaian sumber energi tenaga angin di Indonesia memang kurang mendapat perhatian. Sampai dengan tahun 2004, kapasitas terpasang dari pemanfaatan tenaga angin hanya mencapai $0.5 \mathrm{MW}$ dari $9.29 \mathrm{GW}$ potensi yang ada. Padahal untuk kapasitas pembangkitan listrik tenaga angin di dunia telah berkembang pesat dengan laju pertumbuhan kumulatif sampai dengan tahun 2004 melebihi 20 persen per tahun. Dari kapasitas hanya terpasang $5 \mathrm{GW}$ pada tahun 1995 menjadi hampir $48 \mathrm{GW}$ pada akhir tahun 2004 tersebar dalam 74,400 turbin angin di sekitar hanya 60 negara (Daryanto Y. 2007).

Pada pembangkit listrik tenaga angin atau wind power system memanfaatkan energi angin melalui kincir, untuk menghasilkan energi listrik. Kincir angin ini sangat cocok sekali digunakan masyarakat yang tinggal di pulau-pulau kecil. Secara umum, sistem alat ini memanfaatkan hembusan angin untuk memutar rotor generator. Hembusan dari angin dapat ditangkap balingbaling, kemudian dari putaran baling-baling tersebut akan dihasilkan putaran motor, yang selanjutnya diubah menjadi arus listrik. Pada Wind Power System ini terdiri dari empat bagian utama, yaitu rotor, elektrikal, transmisi, dan kolom. Bagian rotor terdiri dari baling-baling dengan tiga daun, bentuknya menyerupi baling-baling pada pesawat. Dengan bentuk seperti ini diharapkan energi angin yang tertangkap bisa maksimal agar bobotnya lebih ringan. Baling-baling atau kincir angin ini dibuat dengan jari-jari 1,15 meter dan bahannya dibuat dari fiberglass. Untuk mendapat hembusan angin, baling-baling diletakkan pada tower setinggi empat meter. Pada bagian transmisi digunakan sistem katrol dan tali, sistem transmisi ini digunakan untuk menyiasati kekuatan angin yang kecil. Karena kecepatan angin di Indonesia relatif kecil, transmisi ini sangat menguntungkan untuk meningkatkan putaran sebagai peningkatan energi angin.

\subsection{Turbin angin sebagai alternatif sumber listrik}

Berdasarkan sumber energi angin yang sebenarnya berlimpah di Indonesia ternyata belum juga dimanfaatkan sebagai alternatif penghasil sumber listrik. Padahal di berbagai Negara luar negeri, pemanfaatan energi angin sebagai sumber energi alternatif non-konvensional sudah semakin mendapatkan perhatian. Hal ini tentu saja didorong oleh kesadaran terhadap timbulnya krisis energi nasional dengan kenyataan bahwa kebutuhan energi terus ditingkatkan sedemikian besar dengan sumber alternative tenaga angin. Di samping itu, sumber daya alam angin merupakan sumber energi yang tak ada habisnya atau dalam kata lain terbarukan, sehingga pemanfaatan sistem konversi energi angin akan berdampak positif terhadap lingkungan sekitar.

\subsection{Potensi Energi Angin}

Beberapa faktor-faktor yang mempengaruhi besarnya antara lain:

- Pengukuran Data Angin

Dalam studi potensi pemanfaatan tenaga angin dilakukan dengan kerangka kegiatan dengan observasi melalui survei lapangan untuk mendapatkan hasil data primer. Kecepatan dan kekuatan angin pada ketinggian di mana turbin angin dipasang akan diekstrapolasi dari data yang didapat dengan mempertimbangkan kekasaran permukaan setempat dan lapisan batas atmosfir.

- Analisis Potensi Angin

Dalam Analisis potensi angin dapat memberikan informasi mengenai:

- Gambaran pola angin berkala.

- Tahap kecepatan angin rendah dan kecepatan angin tinggi.

- Kecepatan angin di daerah yang tidak jauh dengan lokasi pengukuran.

- Banyaknya energi yang dapat tersedia. 
Semua informasi ini berguna dalam menentukan bagaimana dalam pemanfaatan energi angin pada suatu lokasi tertentu, baik untuk kegunaan mekanikal atau elektrikal. Pada kecepatan angin pada lokasi di mana sistem konversi turbin angin akan di pasang akan dianalisis dan dihitung berdasarkan data yang ada, baik dari sumber BMG maupun dari hasil pengukuran sebagai suplemen dan bahan rujukan tertentu. Kecepatan angin pada lokasi di mana sistem konversi turbin angin akan diletakan penempatannya yang akan dianalisis dan dihitung berdasarkan data yang ada, baik dari sumber BMG maupun hasil pengukuran yang ada. Sehingga dapat memberikan hasil hasil kemampuan dalam mendapatkan energi listrik yang optimum yang diperoleh dari sumber tenaga listrik. Adapun kelompok lokasi kecepatan angin di Indonesia dapat dibagi atas:

Kelompok I: Lokasi dengan kecepatan angin ratarata $1-2,5 \mathrm{~m} / \mathrm{det}$,

Kelompok II: Lokasi dengan kecepatan angin ratarata $2,5-4 \mathrm{~m} / \mathrm{det}$,

Kelompok III: Lokasi dengan kecepatan angin rata-rata 4,5-12 m/det.

\subsection{Tahapan desain bentuk lambung}

Bentuk lambung kapal ini mengacu analisis kekuatan kapal FRP yang berbahan Fiberglass dengan struktur penyusun kerangka yang dirancang kuat tetapi tidak over strength, adanya gading-gading dan penegar dan juga dengan bentuk lambung memiliki transom dapat memberikan perlakuan khusus, karena dalam operasional kapal diperlukan besarnya kecepatan kapal untuk ber-manouver.

\subsection{Kapasitas turbin angin}

Dalam kapasitas turbin angin dapat dikategorikan pada tiga kapasitas yaitu:

1) Kapasitas kecil : sampai $10 \mathrm{~kW}$

2) Kapasitas sedang : $10 \mathrm{~kW}$ s/d $100 \mathrm{~kW}$

3) Kapasitas besar : di atas $100 \mathrm{~kW}$

\section{METODOLOGI PENELITIAN}

\subsection{Tahapan Perancangan}

Tahapan Perancangan sesuai dengan diagram alir dibawah ini

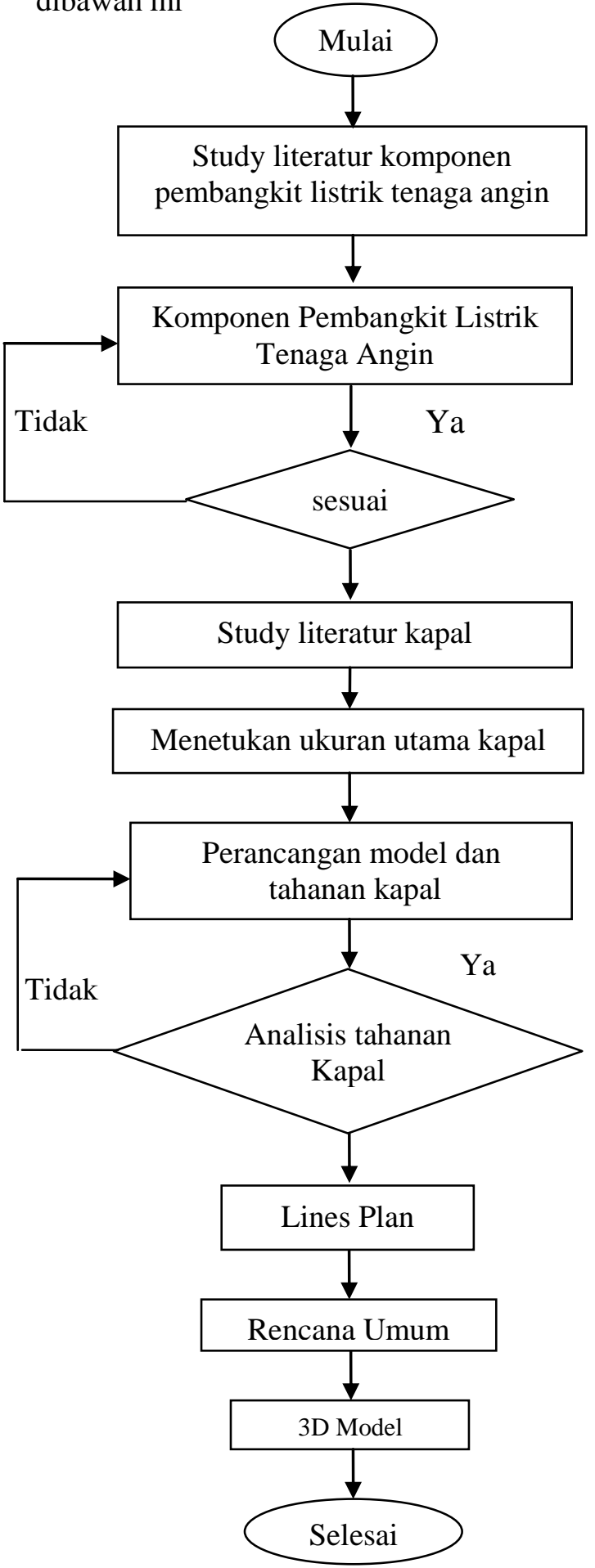

Gambar 3.1. Flowchart tahapan - tahapan desain 


\subsection{Analisis Kebutuhan Desain}

Tahapan - tahapan desain yang digambarkan dalam bentuk flowchart bertujuan untuk mengetahui metode apa yang digunakan dalam perancangan kapal pembangkit listrik tenaga angin ini. Tiap metode dalam flowchart dapat dijelaskan sebagai berikut;

\subsubsection{Study Literatur Komponen Pembangkit} Listrik Tenaga Angin

Study literatur adalah pengumpulan referensi yang bertujuan untuk memperkuat permasalahan serta menggali lebih dalam informasi mengenai perancangan kapal PLTA 15 GT ini. Study literatur dapat diperoleh melalui buku atau dari internet. Dalam hal ini dibutuhkan referensi yang relevan mengenai Komponen pembangkit listrik tenaga angin.

\subsubsection{Perancangan Komponen Pembangkit Listrik}

Tenaga Angin

Setelah melakukan studi literatur yang relevan, selanjutnya adalah merancang komponen komponen pembangkit listrik tenaga angin seperti turbin angin, generator dan motor apa yang digunakan. Serta berapa jumlah turbin yang akan beroperasi pada tiap kapal.

\subsubsection{Study Literatur Kapal}

Study liteatur kapal bertujuan untuk mengetahui ukura utama kapal dan model kapal yang akan dirancang dengan cara mengumpulkan sumber sumber pustaka yang relevan, yang sesuai dengan tujuan perancangan kapal PLTA 15 GT ini.

\subsubsection{Menentukan Ukuran Utama Kapal}

Setelah melakukan studi literatur yang relevan selanjutnya adalah menentukan ukuran utama kapal. Penentuan ukuran utama kapal ini tentunya harus sesuai dengan pembangkit listrik tenaga angin yang beroperasi.

\subsubsection{Perancangan Model dan Tahanan Kapal}

Perancangan model kapal bertujuan untuk menyesuaikan desain kapal dengan pembangkit listrik tenaga angin yang beroperasi, untuk membuat model kapal yang harus dilakukan pertama adalah membuat rencana garis atau lines plan. Sedangkan tahanan kapal adalah kemampuan kapal dalam menahan gaya fluida yang bekerja. Tahanan kapal bergantung dari bentuk lambung kapal, displacement dan kecepatan. Perancangan model dan tahanan kapal tentunya bertujuan untuk mendesain kapal yang efektif dan efisien. Perancangan ini membutuhkan software seperti Maxsurf dan Autocad untuk mendesain sekaligus menghitung.

\subsubsection{Analisis Tahanan Kapal}

Setelah melakukan perancangan, selanjutnya adalah menganalisis apakah rancangan model dan tahanan kapal sudah sesuai dengan standar atau belum. Analisis ini sangat penting karena dari sini dapat diketahui layak tidaknya suatu desain rancangan kapal yang telah dibuat. Jadi alur tahap ini dikatakan dapat atau tidak terpenuhi dalam desain kapal.

\subsubsection{Lines Plan}

Sisi luar lambung kapal berbentuk lengkung pada beberapa kasus terdapat tekukan, penggambaran lambung kapal pada sebidang kertas gambar dinamakan rencana garis (lines plan/ship's lines/ lines), bentuk lambung kapal secara umum harus mengikuti kebutuhan daya apung, stabilitas, kecepatan, kekuatan mesin, olah gerak dan yang penting adalah kapal bisa dibangun.

\subsubsection{Rencana Umum}

Setelah analisis model kapal sudah sesuai, selanjutnya adalah pembuatan rencana umum atau general arrangement. Rencana umum dibuat untuk menentukan atau merncang ruangan di dalam sebuah kapal, baik ukuran maupun tata letaknya. Rencana umum untuk kapal PLTA 15 GT ini tidak begitu banyak mengingat kapal ini merupakan kapal yang relative cukup kecil dan tidak membutuhkan banyak sekat untuk pembagian fungsi ruangan.

\subsubsection{D model}

Merupakan bentuk 3D bentuk lambung kapal yang akan diterapkan pada kapal pembangkit tenaga angin (KPLTA) 15 GT.

\section{a. Perangkat Keras (Hardware)}

Dalam kebutuhan perangkat keras untuk menunjang running modeling desain kapal maka dibutuhkan sebuah perangkat keras yaitu:

a. Laptop dengan processor minimal dual core dan memory $3 \mathrm{~GB}$ 
b. Portable hardisk 2 tB untuk proses simulasi modelling

\section{b. Perangkat Lunak (Software)}

Dalam suatu perancangan kapal yang digunakan saat melakukan perhitungan tahan kapal membutuhkan suatu software guna menunjang sistem tersebut adapun software yang dibutuhkan antara lain
a. Maxsurf
b. AutoCad
c. MS Excell

\subsection{Desain dan Perencanaan Sistem}

Desain kapal pembangkit listrik tenaga angin yang akan dikerjakan dalam penelitian ini, seperti pada gambar 3.2 blok diagram Perencanaan kapal sebagai berikut:

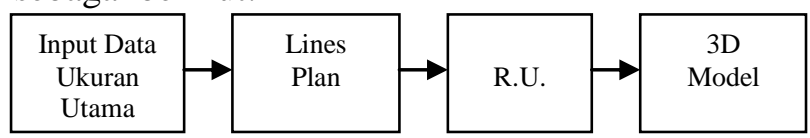

Gambar 3.2. Blok Diagram Perencanaan kapal

\subsubsection{Desain dan Perencanaan Sistem Turbin}

Desain turbin angin yang akan dikerjakan dalam penelitian ini, seperti pada gambar 3.3 blok diagram Perencanaan sistem sebagai berikut:

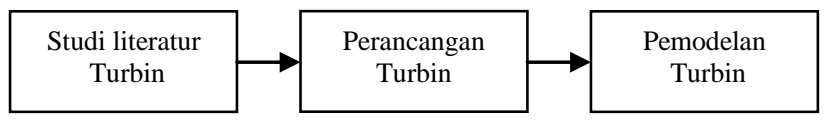

Gambar 3.3 Blok Diagram Perencanaan Sistem Turbin

\section{HASIL DAN PEMBAHASAN}

Perancangan pada Maxsurf

Ukuran utama kapal pembangkit listrik tenaga angin adalah sebagai berikut:

$\begin{array}{lll}\text { Loa } & : 15 & \mathrm{~m} \\ \text { Breadth } & : 7 & \mathrm{~m} \\ \text { Draft } & : 2 & \mathrm{~m} \\ \text { Depth } & : 4 & \mathrm{~m} \\ \text { Vs } & : 7 & \mathrm{kts}\end{array}$

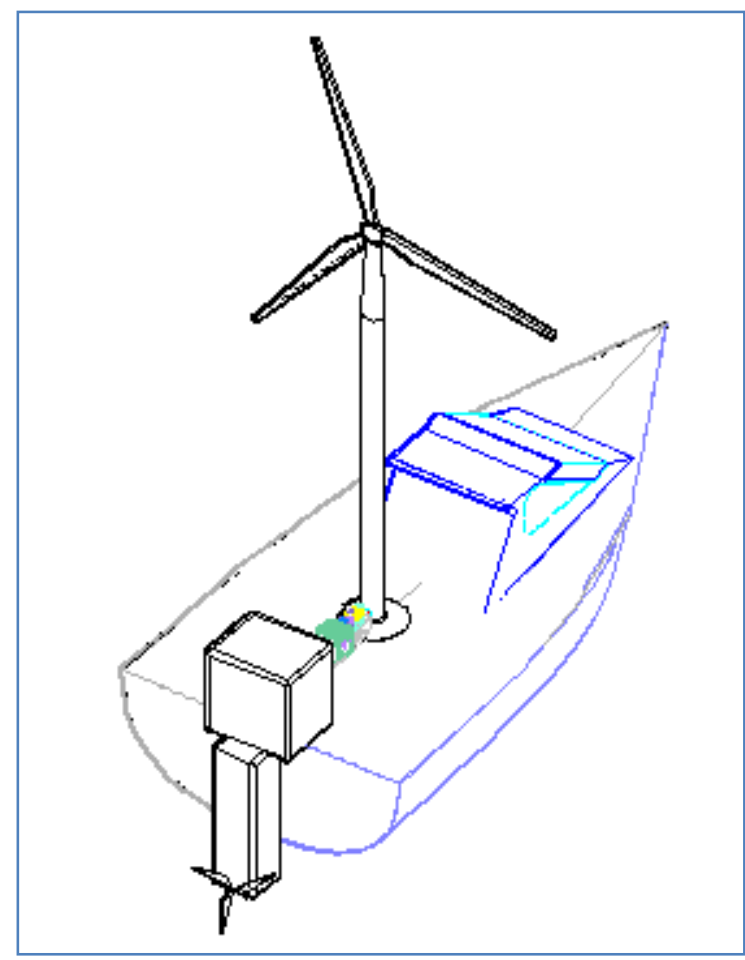

Perancangan model kapal dibuat menggunakan software Maxsurf professional, Pertama buat desain basic dengan default surface. Kapal yang telah dirancang dengan ukuran utama telah jadi dengan hasil sebagai berikut,

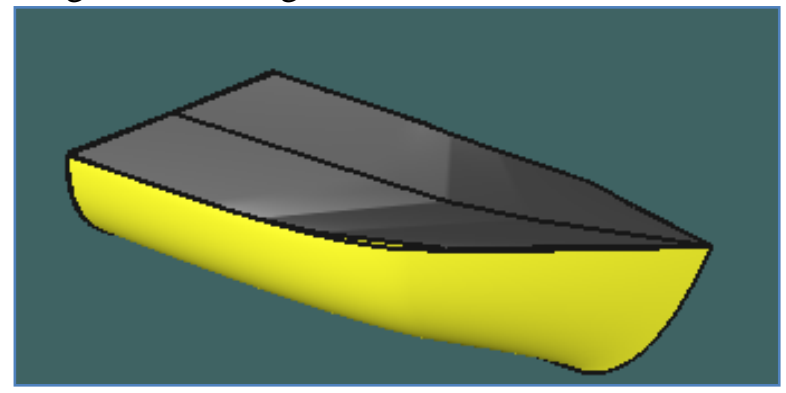

Lalu export tiap windownya menjadi bentuk dxf. File, agar bisa dibuka di AutoCAD. Setelah itu dilakukan proses editing dan desain tingkat lanjut di AutoCAD. 


\subsubsection{Perancangan kapal pada AutoCAD}

Buka file .dxf yang telah di export tadi pada software AutoCAD, lalu gabungkan gambargambar tadi menjadi satu file yang kemudian dijadikan lines plan dan general arrangement.

4.1.2.1 Lines Plan

Edit menjadi lines plan, yang terdiri dari Sheer Plan, Body Plan dan Half Breadth Plan, Seperti berikut;

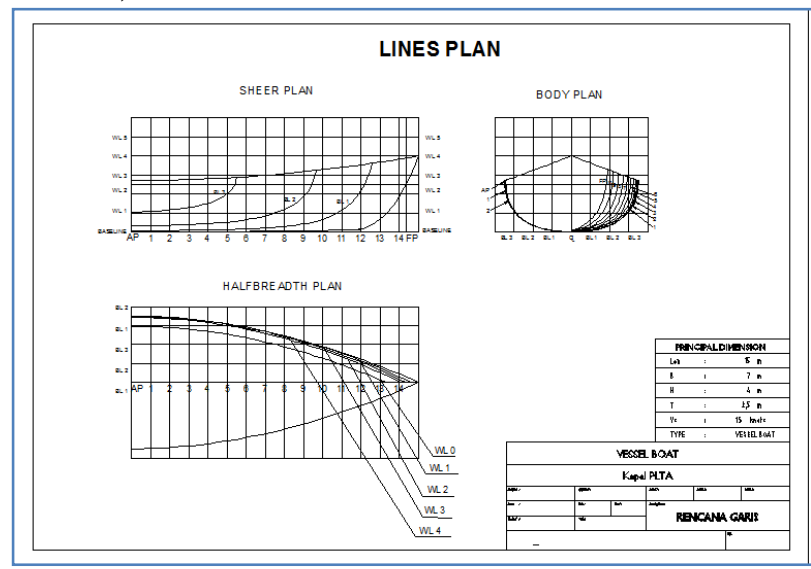

4.1.2.2 General Arrangement

Mengabungkan gambar seperti linesplan, dan dikerjakan tiap view. kemudian tiap ruangan berdasarkan frame spacing atau jarak gading. Untuk general arrangement atau rencana umum, bagi frame dengan offset, frame spacing kapal ini adalah $0.5 \mathrm{~m}$.

Gambar superstructure atau bangunan kapal bagian atas (di atas main deck). Pada kapal ini hanya menggunakan ruang kemudi sepanjang 5 $\mathrm{m}$, karena kapal ini membutuhkan ruangan outdoor yang cukup luas untuk penempatan turbin angin.

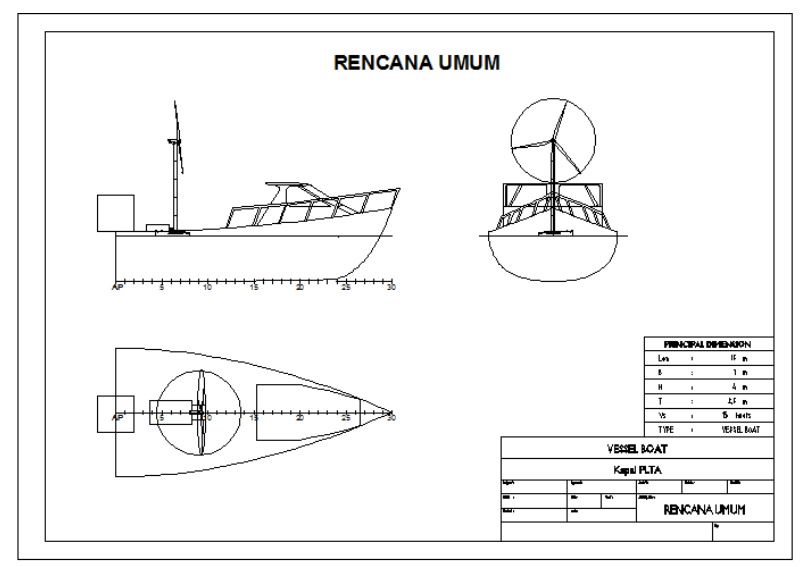

\subsection{Perancangan Turbin dengan AutoCAD}

Gambar turbin angin sesuai dengan ukuran turbin yang direncanakan,

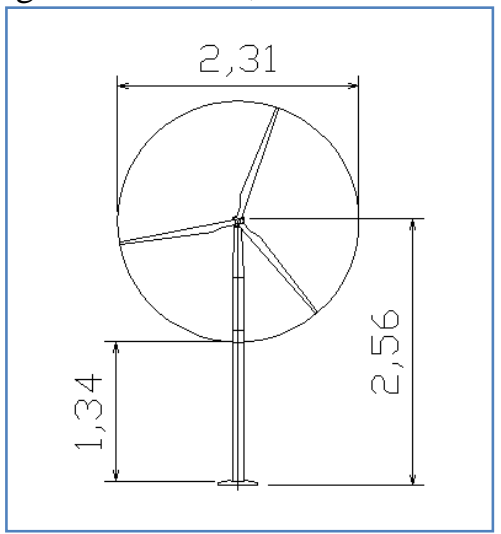

Penggambaran motor dan generator untuk turbin angin menggunakan software AutoCAD 2007 dengan version student edition. Penentuan ukuran atau dimensi turbin menyesuaikan ukuran kapal yang relatif kecil, dalam satuan meter.

\subsection{Analisis Tahanan Kapal dan Kecepatan Kapal}

Analisis daya dan kecepatan kapal dilakukan menggunakan software Hullspeed. Dengan perbandingan kecepatan minimum 5 knots dan kecepatan maximum 7 knots.

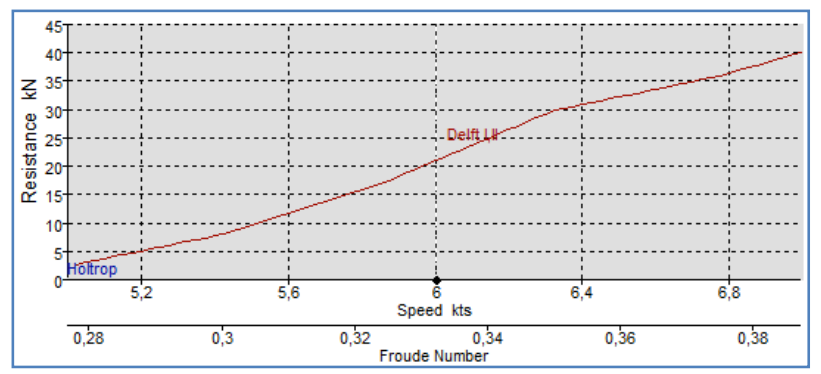

\subsection{Analisis Perbandingan Daya Motor dan Kecepatan Kapal}

Dengan menggunakan software Hullspeed didapatkan grafik perbandingan daya motor dan kecepatan kapal

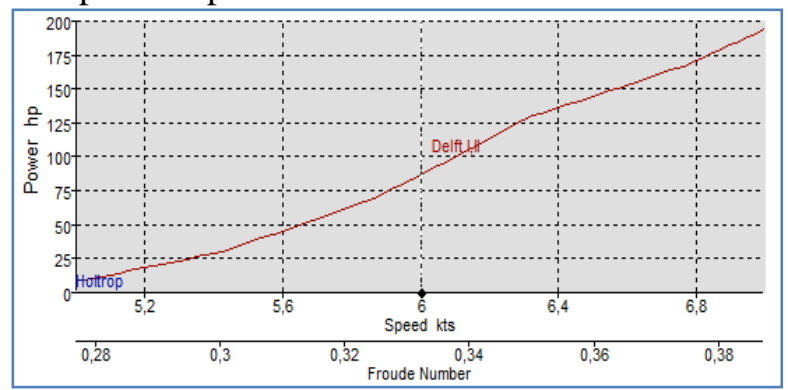


Pada kecepatan yang dimiiki kapal dengan daya motornya adalah $25 \mathrm{HP}$, sehingga dapat dikondisikan dalam pemakaian satu buah tenaga pengerak.

\subsection{Analisis Daya Tahan Kapal Terhadap Ombak}

Berikut ditunjukan bentuk gelombang yang terjadi pada saat operasional kapal bermanouver.

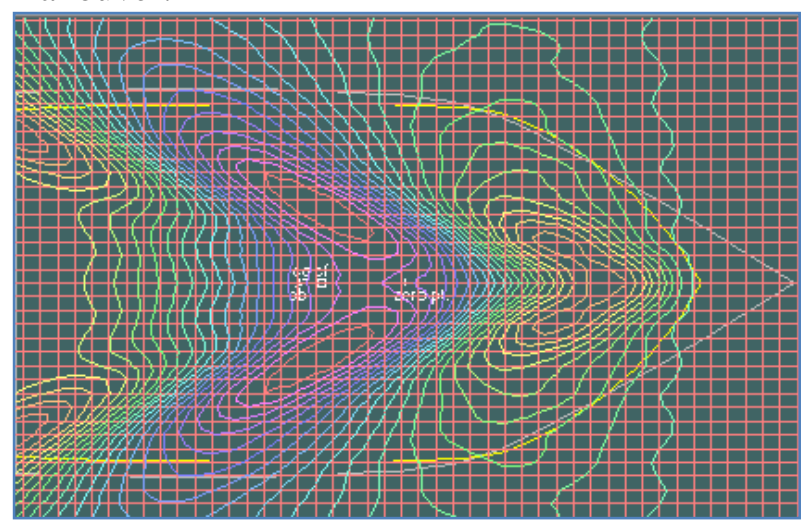

\subsection{D Modeling}

Setelah semua analisis sesuai, maka langkah selanjutnya adalah menjadikan kapal ke dalam bentuk 3 dimensi melalui software Maxsurf dan AutoCAD.

Berikut hasil 3D Modeling kapal Pembangkit Listrik Tenaga Angin;

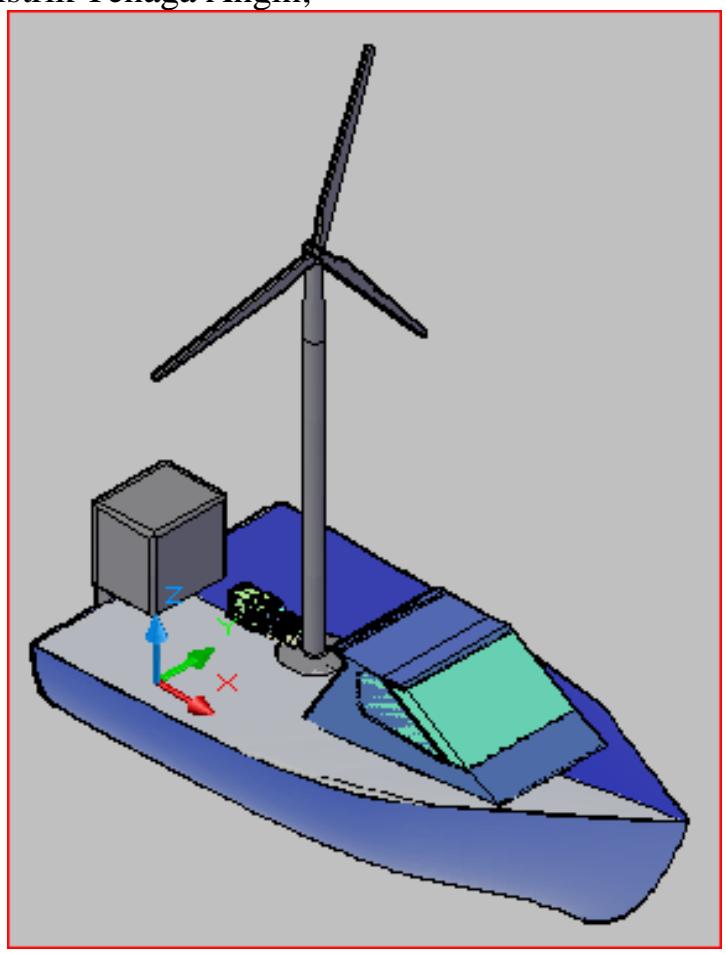

\section{KESIMPULAN DAN SARAN}

\subsection{Kesimpulan}

Setelah melakukan perancangan, didapatkan ukuran utama kapal KPLTA 15 GT yang ditunjukan sebagai berikut:

$\begin{array}{ll}\text { Loa } & : 15 \mathrm{~nm} \\ \text { Breadth } & : 7 \mathrm{~m} \\ \text { Draft } & : 2 \mathrm{~m} \\ \text { Depth } & : 4 \mathrm{~m} \\ \text { Vs } & : 7 \mathrm{kts} \\ \text { DWT } & : 17950 \text { ton } \\ \text { Cb } & : 0.565\end{array}$

5.2 Saran

Perlu dikembangkan mendesain tingkat detail kapal, dengan memasukan faktor - faktor yang mempengaruhi, baik dari segi analisis maupun sistem atau tingkat mass product.

\section{DAFTAR PUSTAKA}

[1] Ableson, Frank. "ship resistance", Maret 2012.

[2] Budianto, Analisa Kekuatan pada Struktur Kapal FRP, Jurnal perkapalan, Volume 10, No.1 Mei 2012

[3] Daryanto Y. 2007. Kajian Potensi Angin Untuk Pembangkit Listrik Tenaga Bayu., Laporan Penelitian Balai PPTAGG-UPTLAGG, Yogyakarta.

[4] Deepak Kumar Lal, Bibhuti Bhusan Dash, A. K. Akella, (2011). Optimization of PV/Wind /micro-hydro for the study area. International Journal on Electrical Engineering and Informatics, vol. 3, no. 3, 307- 325.

[5] Ship Hydrodynamics, Lecture Notes of Propulsion Part. 